\title{
Tau-Reactive Endogenous Antibodies: Origin, Functionality, and Implications for the Pathophysiology of Alzheimer's Disease
}

\author{
Lenka Hromadkova $(1)$ and Saak Victor Ovsepian \\ National Institute of Mental Health, Klecany 25067, Czech Republic \\ Correspondence should be addressed to Lenka Hromadkova; lenka.hromadkova@nudz.cz
}

Received 30 December 2018; Revised 19 March 2019; Accepted 23 July 2019; Published 6 August 2019

Academic Editor: Jacek Tabarkiewicz

Copyright (c) 2019 Lenka Hromadkova and Saak Victor Ovsepian. This is an open access article distributed under the Creative Commons Attribution License, which permits unrestricted use, distribution, and reproduction in any medium, provided the original work is properly cited.

\begin{abstract}
In Alzheimer's disease (AD), tau pathology manifested in the accumulation of intraneuronal tangles and soluble toxic oligomers emerges as a potential therapeutic target. Multiple anti-tau antibodies inhibiting the formation and propagation of cytotoxic tau or promoting its clearance and degradation have been tested in clinical trials, albeit with the inconclusive outcome. Antibodies against tau protein have been found both in the brain circulatory system and at the periphery, but their origin and role under normal conditions and in $\mathrm{AD}$ remain unclear. While it is tempting to assign them a protective role in regulating tau level and removal of toxic variants, the supportive evidence remains sporadic, requiring systematic analysis and critical evaluation. Herein, we review recent data showing the occurrence of tau-reactive antibodies in the brain and peripheral circulation and discuss their origin and significance in tau clearance. Based on the emerging evidence, we cautiously propose that impairments of tau clearance at the periphery by humoral immunity might aggravate the tau pathology in the central nervous system, with implication for the neurodegenerative process of $\mathrm{AD}$.
\end{abstract}

\section{Introduction}

Alzheimer's disease $(\mathrm{AD})$ is a progressive neurodegenerative disorder and the most common cause of dementia in the elderly population. Cognitive decline, memory loss and related clinical symptoms affecting everyday activities signify the advanced stage of the pathology, preceded by preclinical and mild cognitive impairment (MCI) stages. MCI is a prodromal process, characterized by the onset of the earliest cognitive symptoms including memory dysfunctions and other cognitive impairments, which in most of the cases gradually evolve into a clinical AD [1]. In-depth analysis of pathological changes and testing potential therapeutics for the treatment of MCI appears to be of major significance, offering a window for early intervention in the disease process, with currently no cure available for AD. Neurofibrillary tangles (NFTs) composed of tau protein along with senile plaques formed by amyloid beta $(\mathrm{A} \beta)$ peptide are the most consistent histopathological hallmark of the disease $[2,3]$. Tau protein belongs to the family of microtubule-associated proteins (MAPs) and is localized predominantly in axonal projections of neurons [4]. It plays a critical role in the microtubule assembly and stabilization [5], contributing to cytoskeleton reorganization and regulation of axonal transport, via dynamic interactions with microtubules [6-9]. Under neurodegenerative conditions such as $\mathrm{AD}$ and other tauopathies, aggregation of pathologically modified variants of tau protein and their abnormal sorting lead to the disruption of normal neuronal functions and formation of intracellular tangles and cytotoxic soluble oligomers. Therefore, tau protein is considered as one of the key ingredients involved in disease and, as such, a warranted diagnostic and therapeutic target.

Due to the critical involvement of the immune system in the pathobiology of $\mathrm{AD}$, antibody-based therapies are under close scrutiny as a promising disease-modifying strategy. To this end, circulating immunoglobulins reactive with $\mathrm{A} \beta$ peptides and tau protein are of special research and translational interest [10]. While much progress has been made in this direction, debate persists as to whether disease-related changes in the level and activity of these antibodies are beneficial or harmful. Until recently, most of the research 
was focused on natural $\mathrm{A} \beta$ peptide-reactive antibodies [11]. Nevertheless, in clinical trials, therapeutic strategies based on anti- $\mathrm{A} \beta$ treatments turned disappointing, suggesting also other major players $[12,13]$. Tau pathology, on the other hand, correlates better with progression of the clinical AD and neurodegenerative process and can evolve independently from $\mathrm{A} \beta$-related impairments [14]. Accordingly, various anti-tau antibodies have been produced and tested for their putative protective role $[15,16]$.

Throughout this review, we discuss emerging data on tau-reactive antibodies in circulatory systems and consider their relevance to tau homeostasis and dysregulations in $\mathrm{AD}$. We highlight advances and stress the lack of consensus in the field, along with an urgent need in in-depth research, to elucidate the role of humoral immunity in tau homeostasis. Finally, we consider the possible significance of tau-reactive antibodies for countering the progression of the neurodegenerative process in $\mathrm{AD}$.

\section{Tau Protein as a Potential Immunogen}

Although tau is an intracellular protein with the main localization in neuronal axons [4], it also belongs to the core CSF biomarkers of $\mathrm{AD}$, with trace amounts detected in the blood.

In the CNS, tau protein occurs in six isoforms due to alternative splicing [17] and as a natively unfolded protein is subjected to many posttranslational modifications, mostly phosphorylation [18]. Levels of total tau and tau phosphorylated at threonine 181 are elevated in CSF of $\mathrm{AD}$ and $\mathrm{MCI}$ due to $\mathrm{AD}$ compared to age-matched controls [19]. However, there are marked differences in absolute levels of $\mathrm{AD}$ biomarkers in CSF, including tau protein, reported in various studies, even with the use of the same ELISA variants for measurements [20].

Until recently, there was no possibility of measuring tau protein in peripheral fluids, due to lack of sensitive methods. Research for blood-based biomarkers of neurodegenerative diseases, however, facilitated the development of a SimoaHD1-based novel single-molecule ELISA capable of detecting minuscule amounts of tau [21]. With this method, total tau protein levels in the plasma were quantitatively evaluated in healthy volunteers, $\mathrm{MCI}$, and $\mathrm{AD}$ patients, revealing therein far lower concentrations (units of $\mathrm{ng} / \mathrm{L}$ ) as compared to the CSF $[22,23]$. The amount of tau reported in patients with clinical $\mathrm{AD}$ was somewhat higher as compared to that in MCI and controls, although there was a considerable overlap of readouts from different groups [22, 24-26]. At this point, there is pressing need in large cohort longitudinal studies with the use of ultrasensitive assays capable of detecting not only the amounts of regular tau protein but also its fragments, as well as posttranslationally modified variants prevalent in $\mathrm{AD}$. Using newly developed assay, Tatebe and colleagues [27] in a recent small-scale study demonstrated significantly higher levels of phosphorylated p181 tau protein (P-tau) in the plasma in AD patients as compared to healthy controls, a finding confirmed also by other groups $[28,29]$. Intriguingly, the most toxic tau oligomers have been detected in the serum not only in
$\mathrm{AD}$ patients but also in MCI groups and in healthy volunteers, with the lowest amounts in the MCI cohort [30]. These observations suggest that various modifications of tau protein in the periphery could serve as an antigen stimulating an immunological response, with the production of a range of tau-reactive antibodies.

Because of physiological protection of the brain by blood-brain barriers (BBB), an increase in the amount of neuronal proteins in peripheral blood circulation suggests impairments of the barriers [31]. Like AD, stroke, traumatic brain injuries (TBI), and other conditions are accompanied by the disruption of the $\mathrm{BBB}$ with increased permeability [32]. Under these circumstances, the loss of neurovascular defense shield unmasks self-antigens of the central nervous system, activating immune response with the production of autoantibodies in the periphery. In TBI, for example, disruption of the BBB causes a significant rise in the levels of astrocytic proteins GFAP and S100b in the plasma, which stimulates the production of anti-GFAP and anti-S100b autoantibodies of the IgG subtype [33,34]. Disruption of vascular barriers of the brain has been suggested to contribute to rise in the levels of tau in $\mathrm{AD}$ [35-38] as well as in frontotemporal dementia (FTD) [39] and Down syndrome [40]. Importantly, loss in BBB integrity occurs also in normal aging as well as in MCI [41-43], enabling bidirectional crossing of several tau protein forms across, albeit with different kinetics [44]. Another source of peripheral tau is blood platelet cells, know also to carry trace amounts of tau protein [45]. Interestingly, an increase of high molecular weight (HMW) forms of tau and a decrease of low molecular weight tau (LMW) were reported in blood platelets of $\mathrm{AD}$, compared to healthy controls [45-48]. Last but not least, in peripheral circulation, tau protein was found in association with exosomes originated from the CNS [49-52], which have been traditionally viewed as mediators of tau clearance [53].

The increased levels of tau protein in the peripheral circulation of $\mathrm{AD}$ patients could potentially reflect two pathological processes occurring in the brain: (1) BBB disruptions and (2) extensive axonal damage with neurodegeneration. Despite the rise of the level of tau protein in the blood, as noted above, levels of tau-reactive antibodies in serum at $\mathrm{MCI}$ and clinical $\mathrm{AD}$ remain unchanged [54-57]. One possible explanation for this conundrum is that with the disruption of the $\mathrm{BBB}$, newly formed tau-reactive autoantibodies may be recruited from the circulation into the brain, which could aggravate the pathological process through adding extra immunological burden, a notion supported by higher IgG reactivity within damaged neurons and NFTs in AD [58, 59]. Alternatively, in $\mathrm{AD}$ and other related neurodegenerative diseases, the peripheral immune system is severely compromised, contributing to paradoxical reduction of the levels of tau-reactive antibodies in the blood of diseased subjects, as compared in controls [60]. Considering wide variations in physiological and pathological variants of tau protein, the pool of tau-reactive antibodies in circulation is likely to comprise a heterogeneous mixture against various tau epitopes with distinct characteristics, an 
important factor to be considered in the future research of tau-reactive antibodies.

\section{Tau-Reactive Antibodies in Circulatory Systems}

The presence of tau-reactive autoantibodies of both IgG and IgM has been proven in sera and cerebrospinal fluid of $\mathrm{AD}$ patients as well as in healthy controls [54-57, 60-64], summarized in Table 1. Antibodies directed against tau protein are also shown in various intravenous immunoglobulin (IVIG) products and pooled immunoglobulin subtype G from large cohorts of healthy donors [64-68]. Quantitative evaluation of tau-reactive antibodies in the blood has been reported by several groups [54-57, 60-62]. Even though different tau variants have been used as antigens in ELISA reports in these publications, surprisingly, no statistically significant differences were found between healthy controls and AD patients. Only higher levels of tau-reactive antibodies were detected with respect to gender in MCI due to the $\mathrm{AD}$ group [56]. Klaver and colleagues demonstrated elevated titers of serum tau-reactive antibodies against tau fragment 196-207 phosphorylated at residues 199/202 in a group of MCI subjects [62]. Remarkably, in several trials, the levels of tau-reactive antibodies in the serum of $\mathrm{AD}$ patients were lower compared to controls and decline further with advancement of the pathology [60].

Relatively similar levels of tau-reactive antibodies in $\mathrm{AD}$ and controls detected in most studies call into question their general physiological significance and potentially beneficial role under pathological circumstances. The ubiquitous occurrence of tau-reactive antibodies in sera and cerebrospinal fluid of healthy individuals and in IVIG products suggests that they are unlikely to be harmful $[57,65]$. But to date, it can only be speculated whether they may have protective effects against tau pathology in $\mathrm{AD}$ or other tauopathies, by facilitating the clearance of misfolded tau, blocking its polymerization, or perhaps degrading tau aggregates [69]. It is worth stressing that specific tau-reactive antibodies may be also generated in response to presentation of tau as a new self-antigen, which might contribute to the immune imbalance in $\mathrm{AD}$, and potentially lead to neuroinflammatory response, aggravating the progression of the disease.

Overall, while overwhelming data indicate the presence of tau antibodies in circulatory liquids in the brain and at the periphery, debate persists over their origin and relevance to normal physiology and pathobiology of $\mathrm{AD}$. Whether these immunoglobulins are naturally occurring antibodies, mostly with poly/cross-reactive profile, or whether they are generated as more specific antibodies after the exposure of tau protein as an antigen with newly exposed epitopes to the peripheral immune system remains to be determined. As discussed below, an in-depth analysis of these important issues has led recently to several interesting discoveries, bringing more clarity in complex affairs of the immune system and the brain under healthy and diseased conditions.

\section{Naturally Occurring Tau-Reactive Antibodies}

The generalized assumption that low-affinity polyreactive natural anti-tau antibodies have beneficial functions while high-affinity nonreactive autoantibodies are harmful, while instructive, requires rigorous experimental validation. With growing recognition of major immunogenic components in $\mathrm{AD}$ and other chronic neurodegenerative diseases and raising interest in immunotherapy, there is a pressing need in the research of naturally occurring endogenous antibodies directed against brain antigens $[59,70]$. Whether peripheral antibodies reactive with tau protein belong to natural antibodies with more beneficial function or they are more likely to be formed due to autoimmunity process is still unknown.

The demonstration of the prevalence of tau-reactive natural human antibodies in peripheral circulation presents a major advance [57]. Their occurrence in circulation from early childhood suggests the independence of this process from exogenous antigens and, as such, perhaps acting as a part of the innate immunological repertoire, possibly involved in the regulation of tau homeostasis under physiological and pathological conditions. Thus, tau-reactive antibodies could be a part of a pool of naturally occurring, germline gene-coded antibodies produced independently of foreign antigens, which constitute approximately two-thirds of total serum immunoglobulins. As they are not subjected to affinity maturation and thus contain none or very few somatic mutations, they are associated with polyspecific (polyreactive) and variable, predominantly low, antigenbinding affinities $[71,72]$ and are assumed to have many crucial physiological roles and contribute significantly towards the maintenance of immune homeostasis [73-76]. In 2018, the first report of the longitudinal evolution of tau antibody levels in the serum of AD and controls was published [60]. Surprisingly, a gradual decrease in serum anti-tau antibodies in the course of $\mathrm{AD}$ compared to controls was found, which may reflect a progressive loss of tau-reactive antibodies with possible immunomodulatory functions during the AD-linked neurodegeneration. This observation, however, requires independent verification, using a larger collection of samples.

Beside predominantly beneficial natural antibodies, autoantibodies causing a range of chronic autoimmune disorders can be also produced, typically due to dysregulations of the immune system [77, 78]. These antibodies are almost exclusively monoreactive with higher affinities to particular self-antigens. Several hypotheses, explaining how a part of antibody portfolio switches into pathogenic autoantibodies, have been suggested $[79,80]$, with the most acknowledged one known as the autoimmune hypothesis of $\mathrm{AD}[58,81]$. In brain regions most severely affected by $\mathrm{AD}$, Ig-positive neurons are in excess, as compared to age-matched controls [59]. Moreover, many of these Ig-positive neurons show morphological signs of neurodegeneration and express markers of classical complement pathway and apoptosis [82]. Blennow and colleagues demonstrated the increased intrathecal synthesis of either IgM or IgG in some AD patients, which suggested the activation of immune response by the degenerative process [83]. Recently, increased intrathecal synthesis of anti-tau antibodies was shown in multiple 


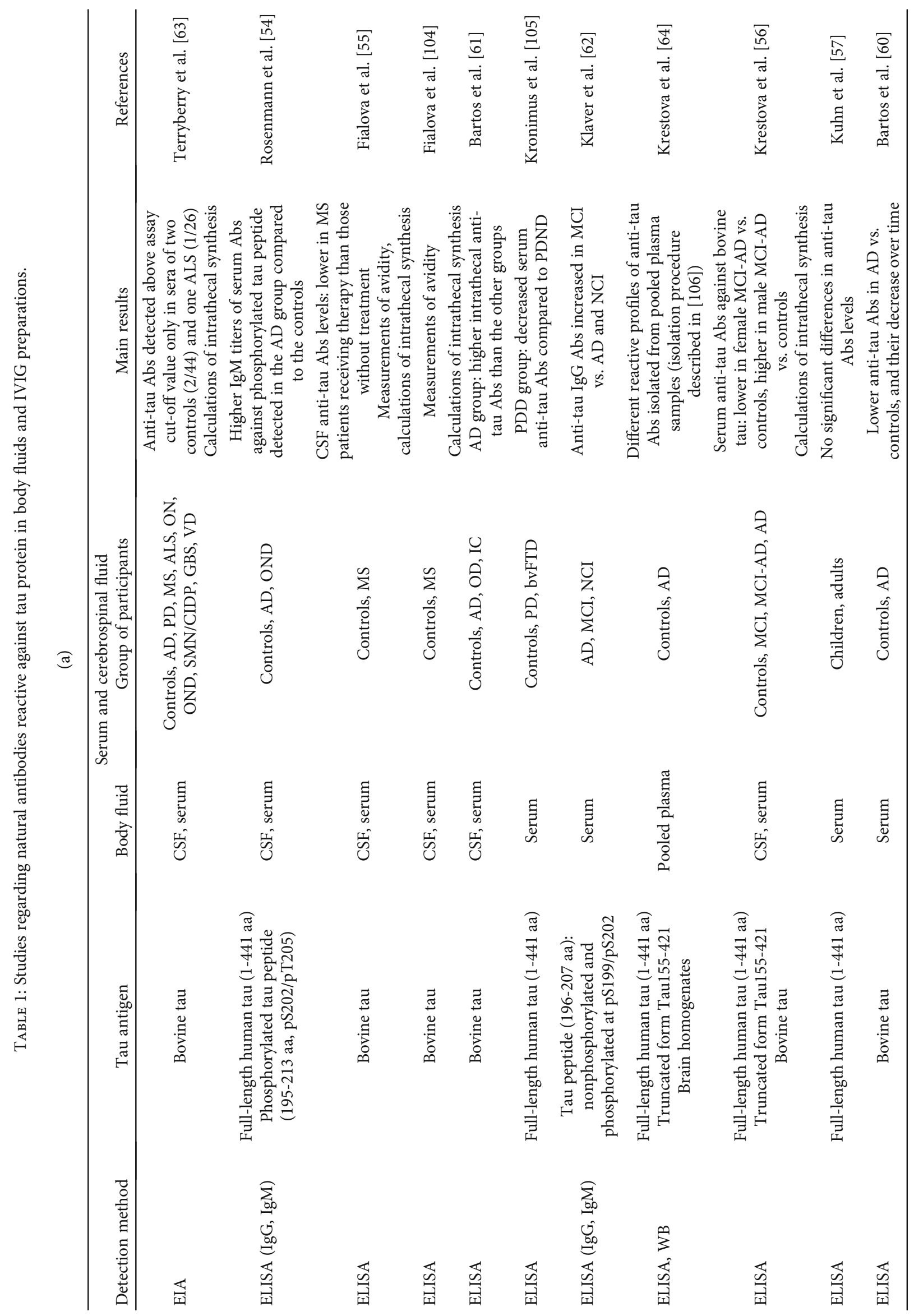




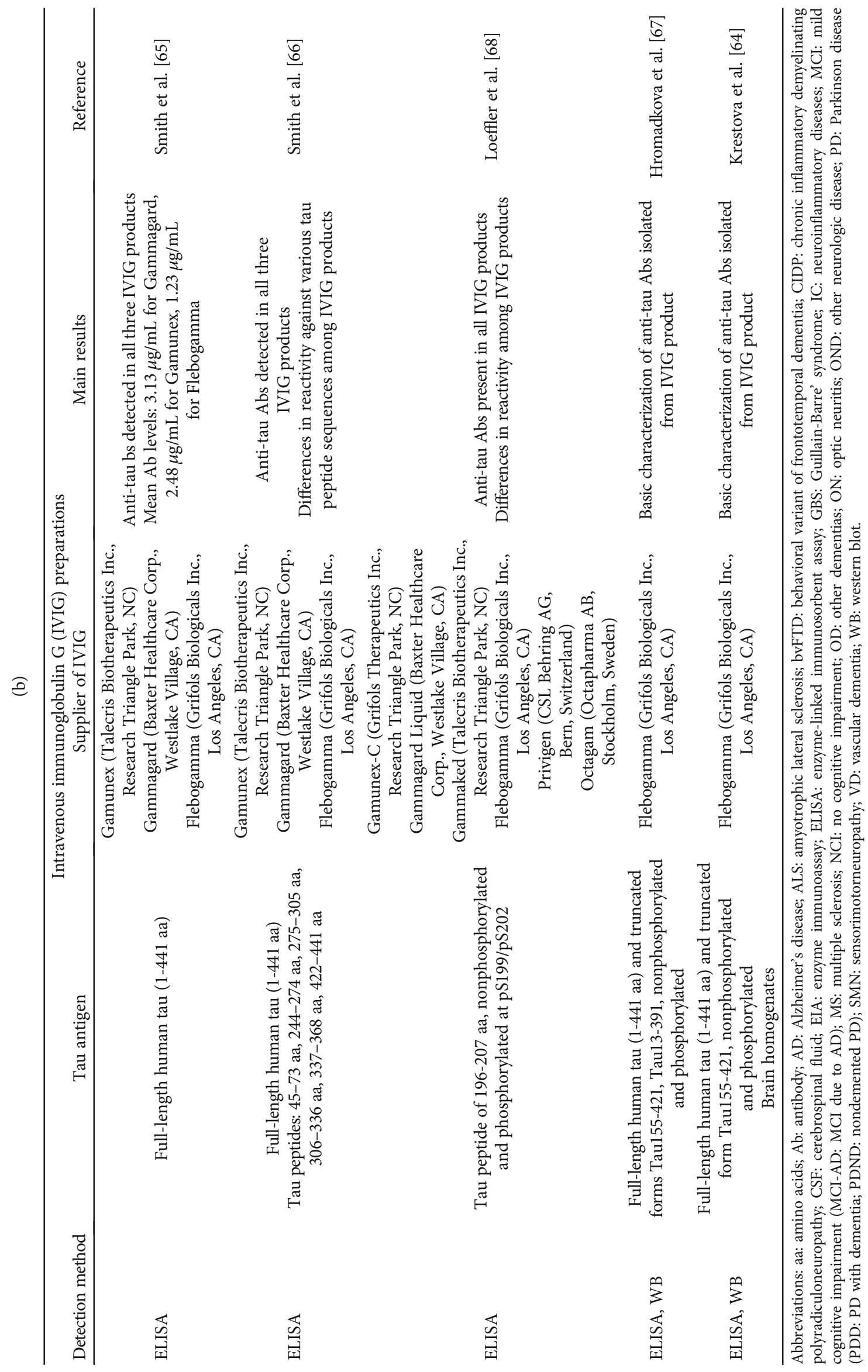


sclerosis [55] and confirmed in $\mathrm{AD}$ [61]. Elevated intrathecal synthesis of anti-tau antibodies, reflecting the activation of the specific humoral immune response to extracellular tau released by the neurodegenerative process, can be perceived as an autoimmune response within the CNS. Whether the pool of anti-tau antibodies produced in the brain exacerbates the pathogenic process or counters it remains to be established. With the progression of $\mathrm{AD}$, peripheral tau protein levels also become higher, suggesting progressive impairment of the BBB, with tau release in peripheral circulation, where it might serve as an antigen in the formation of tau-reactive antibodies.

To summarize, antibodies reactive with tau protein are more likely to be represented by a mixture of both, natural antibodies without antigen-dependent maturation and more specific antibodies formed after the exposure to tau as an immunogen. The crucial question that remains to be addressed is whether the antibodies against pathological tau forms may help their clearance or whether they bind with tau variants and thus contribute towards the inflammation and harmful immunological response unfolding in $\mathrm{AD}$.

\section{Reactivity of Circulating Anti-Tau Antibodies}

Using circulating tau-reactive antibodies from the peripheral circulation, it was shown that these antibodies can recognize abnormally modified tau forms and vary in a great deal in their characteristics [64, 67]. These findings are in general agreement with miscellaneous and highly complex transformation, which tau protein undergoes throughout the initial aggregation process and formation of paired helical filaments (PHFs) followed by more dynamic changes involving truncation and phosphorylation during the polymerization process (the ordered series of events in NFTs evolution are described at [84-88]). The same processes also lead to the formation of oligomeric tau variants, which are thought to be the most toxic species, contributing towards spreading of tau pathology and neurodegeneration [89]. In light of this, an in-depth study with characterization of the activity of circulating tau-reactive antibodies against physiological and pathological tau forms is well warranted. Our preliminary data showed that tau-reactive antibodies extracted from AD plasma interact with monomeric tau forms, both recombinant and derived from native brain homogenates. In contrary, antibodies isolated from IVIG and pooled from the plasma of healthy controls showed stronger reactivity with recombinant fragmented tau (155-421 aa) protein and with more aggregated forms present in brain homogenates of $\mathrm{AD}[64,67]$. So far, these observations support the notion that the humoral immune system may be involved in controlling the occurrence of abnormal tau protein forms under physiological conditions. Overall, it emerges that tau protein leaking from the brain into the peripheral circulatory system is subjected to fast degradation and elimination by endogenous tau-reactive antibodies, a process which seems to be compromised in AD (Figure 1). The latter is supported by recent data showing that enhancement of tau clearance in the periphery is an effective means for ameliorating tau pathology in the central nervous system of murine AD models and in human brain [90].

\section{IVIG for AD Immunotherapy}

Aberrations of tau protein conformation play a major role in the pathobiology of $\mathrm{AD}$; therefore, antibody-based immunotherapy directed against structurally modified and aggregated tau variants presents an attractive therapeutic strategy [10]. Pathological changes in tau protein occurring during MCI and $\mathrm{AD}$ progression are, however, highly complex and not strictly tied to specific molecular conformation or mechanism. The therapeutic use of IVIG products prepared from the plasma of healthy controls enriched with a wide range of natural antibodies is therefore highly warranted, offering a miscellaneous solution. Over recent years, numerous beneficial immunomodulatory and anti-inflammatory effects of IVIG have been documented upon their use for the treatment of some immune-mediated neurological disorders [91-93]. IVIGs have been also tested in several clinical trials with $\mathrm{AD}$ and MCI patients. Unfortunately, the phase III clinical trials have not fulfilled positive expectations staged by promising results of the initial phase I and II trials [94-96]. Despite the disappointing outcome so far, several IVIG clinical trials are nevertheless currently ongoing $[97,98]$. Intense research is also on its way towards a better characterization of antibodies presented in IVIGs that are specifically directed against proteins relevant to the pathobiology of $\mathrm{AD}$. Based on these studies, it is recommended to use disease-specific IVIG preparations enriched with target-specific antibodies [70, 99].

To the best of our knowledge, to date, only five reports analyzed IVIG products containing tau-reactive antibodies [64-68], summarized in Table 1. After the pioneering report presenting the first evidence for the presence of natural antibodies directed to recombinant human full-length tau in three IVIG products [65], studies have been undertaken to show also the enrichment of IVIGs with antibodies against various tau regions [66] and $\mathrm{AD}$-specific phosphorylated tau forms [67]. In all these reports, tested IVIG products contained autoantibodies reactive to tau antigens, with their levels significantly varying among different IVIG products. The latter possibly reflect variations in specific antibody concentrations amongst donor pools used for plasma collection, as well as differences in procedures applied for antibody isolation and purification $[65,100]$. The lower in vitro binding affinity for antibodies might also contribute to general variability of the research outcome [101]. Finally, polyvalent binding of immunoglobulins needs to be taken into account, to accurately determine the concentrations of a specific natural antibody in complex samples such as a serum, plasma, and IVIG [102].

\section{Closing Remarks}

Throughout this study, we reviewed recent evidence concerning the origin and functionality of tau-reactive antibodies in the circulatory systems of the brain and periphery and discussed their relevance to pathophysiology and therapy of $\mathrm{AD}$. Although much progress has been made in this direction, numerous basic and translational questions remain unanswered, requiring new thinking and in-depth research. There is also a major need in new assays with higher 


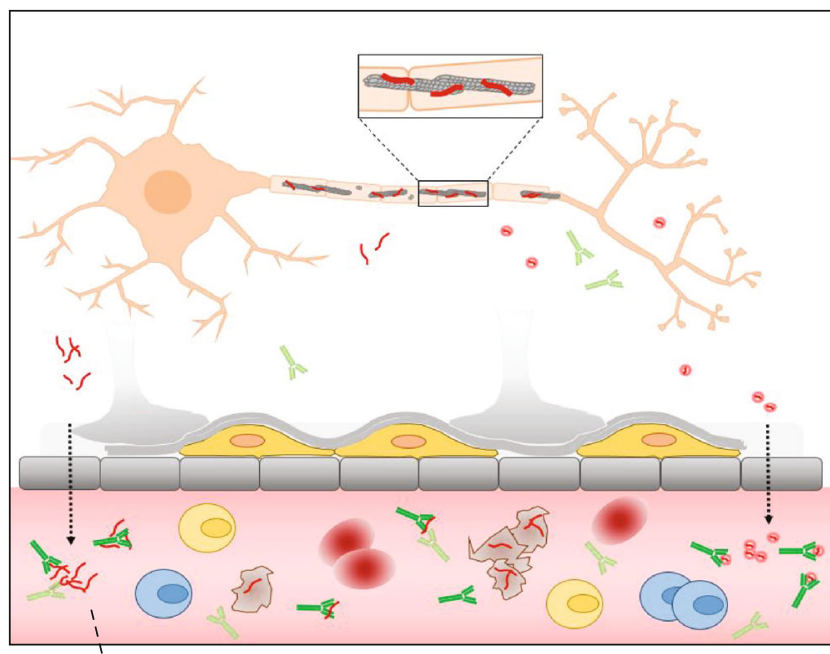

(a)

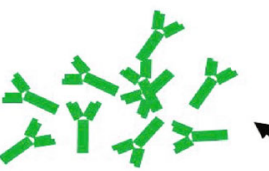

Tau-reactive autoantibodies

APCs

with tau

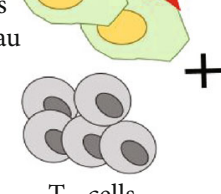

$\mathrm{T}_{\mathrm{H}}$ cells

() Tau protein

柆 Neurofibrillary tangles

Microtubule

a Neuronal derived exosome

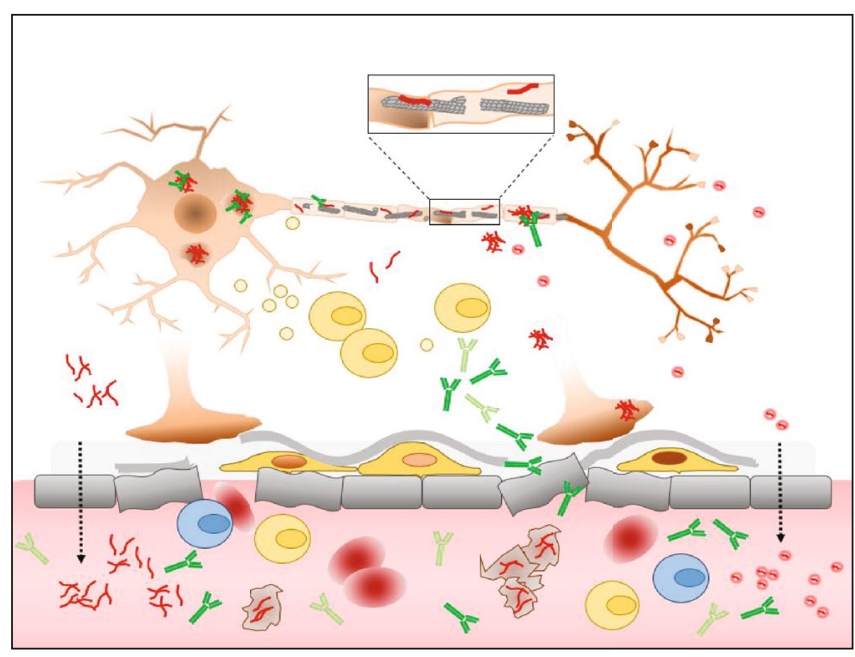

(b)

FIGURE 1: Schematic illustration of the concept of circulating tau-reactive antibodies. Tau protein is present in blood circulation where it may serve as an immunogen for the production of tau-reactive autoantibodies. In the periphery, there is a repertoire of natural antibodies, which may cross-react with tau and which help to maintain immune homeostasis. (a) illustrates physiological condition where the blood-brain barrier (BBB) is intact and the small amounts of tau efflux to the periphery is balanced by tau clearance and degradation. (b) illustrates pathological condition, such as in $\mathrm{AD}$. Under this circumstance, $\mathrm{BBB}$ is impaired and, as a result of many large immunogenic molecules, including tau protein, leaks across barriers into peripheral circulation and vice versa, into the CNS. The latter is thought to aggravate the neuroinflammation and neurodegenerative process in AD. APC $=$ antigen-presenting cell.

sensitivity, for detection and quantification of a wide variety of tau proteins, as well as antibodies reactive to tau, which will allow better validation of the research and therapeutic interventions, including the use of IVIG immunotherapy. Important lessons should be learned from disappointing outcomes in clinical trials, which testify for the incompleteness of our understanding of the biology of autoantibodies and pathophysiology of AD. Arguably, the most exciting outcome of recent studies is the recognition that throughout evolution, a powerful natural mechanism has been set to maintain the homeostasis of tau protein and facilitate its clearance in peripheral circulation when in excess, which can be exploited and guided for therapeutic benefit. With incentives getting higher for effective $\mathrm{AD}$-modifying therapies, reviewed herein recent advances in research of tau-reactive antibodies and their role in tau clearance is likely to become an important part of gradually emerging complex solution to the $\mathrm{AD}$ in the foreseeable future.

\section{Disclosure}

The manuscript is based on a chapter in a thesis with the following link: https://dspace.cuni.cz/bitstream/handle/20.500.11956/ 102651/140065783.pdf?isAllowed $=y \&$ sequence $=1$ [103] .

\section{Conflicts of Interest}

The authors have declared no conflict of interest. 


\section{Acknowledgments}

This work was supported by the project No. LO1611 with a financial support from the MEYS under the NPU I program.

\section{References}

[1] C. R. Jack Jr., D. S. Knopman, W. J. Jagust et al., "Hypothetical model of dynamic biomarkers of the Alzheimer's pathological cascade," The Lancet Neurology, vol. 9, no. 1, pp. 119-128, 2010.

[2] L. M. Ittner and J. Götz, "Amyloid- $\beta$ and tau-a toxic pas de deux in Alzheimer's disease," Nature Reviews Neuroscience, vol. 12, no. 2, pp. 67-72, 2011.

[3] S. V. Ovsepian, V. B. O’Leary, L. Zaborszky, V. Ntziachristos, and J. O. Dolly, "Amyloid Plaques of Alzheimer's Disease as Hotspots of Glutamatergic Activity," The Neuroscientist, article 1073858418791128, 2018.

[4] L. I. Binder, A. Frankfurter, and L. I. Rebhun, "The distribution of tau in the mammalian central nervous system," Journal of Cell Biology, vol. 101, no. 4, pp. 1371-1378, 1985.

[5] H. Kadavath, R. V. Hofele, J. Biernat et al., "Tau stabilizes microtubules by binding at the interface between tubulin heterodimers," Proceedings of the National Academy of Sciences of the United States of America, vol. 112, no. 24, pp. 75017506, 2015.

[6] M. Kempf, A. Clement, A. Faissner, G. Lee, and R. Brandt, "Tau binds to the distal axon early in development of polarity in a microtubule-and microfilament-dependent manner," The Journal of Neuroscience, vol. 16, no. 18, pp. 55835592, 1996.

[7] B. Trinczek, A. Ebneth, E. M. Mandelkow, and E. Mandelkow, "Tau regulates the attachment/detachment but not the speed of motors in microtubule-dependent transport of single vesicles and organelles," Journal of Cell Science, vol. 112, no. 14, pp. 2355-2367, 1999.

[8] R. Dixit, J. L. Ross, Y. E. Goldman, and E. L. F. Holzbaur, "Differential regulation of dynein and kinesin motor proteins by tau," Science, vol. 319, no. 5866, pp. 1086-1089, 2008.

[9] A. Elie, E. Prezel, C. Guérin et al., "Tau co-organizes dynamic microtubule and actin networks," Scientific Reports, vol. 5, no. 1, article 9964, 2015.

[10] T. Wisniewski and F. Goni, "Immunotherapeutic approaches for Alzheimer's disease," Neuron, vol. 85, no. 6, pp. 11621176, 2015.

[11] J.-P. Bach and R. Dodel, "Naturally occurring autoantibodies against $\beta$-amyloid," in Naturally Occurring Antibodies (NAbs), pp. 91-99, Springer, New York, NY, USA, 2012.

[12] H. Hampel, L. S. Schneider, E. Giacobini et al., "Advances in the therapy of Alzheimer's disease: targeting amyloid beta and tau and perspectives for the future," Expert Review of Neurotherapeutics, vol. 15, no. 1, pp. 83-105, 2015.

[13] J. Folch, D. Petrov, M. Ettcheto et al., "Current research therapeutic strategies for Alzheimer's disease treatment," Neural Plasticity, vol. 2016, 15 pages, 2016.

[14] J. T. Pedersen and E. M. Sigurdsson, "Tau immunotherapy for Alzheimer's disease," Trends in Molecular Medicine, vol. 21, no. 6, pp. 394-402, 2015.

[15] P. Novak, E. Kontsekova, N. Zilka, and M. Novak, “Ten years of tau-targeted immunotherapy: the path walked and the roads ahead," Frontiers in Neuroscience, vol. 12, p. 798, 2018.
[16] E. M. Sigurdsson, “Tau immunotherapies for Alzheimer's disease and related tauopathies: progress and potential pitfalls," Journal of Alzheimer's Disease, vol. 66, no. 2, pp. 855-856, 2018.

[17] M. Goedert and R. Jakes, "Expression of separate isoforms of human tau protein: correlation with the tau pattern in brain and effects on tubulin polymerization," The EMBO Journal, vol. 9, no. 13, pp. 4225-4230, 1990.

[18] L. Martin, X. Latypova, and F. Terro, "Post-translational modifications of tau protein: implications for Alzheimer's disease," Neurochemistry International, vol. 58, no. 4, pp. 458-471, 2011.

[19] N. Mattsson, H. Zetterberg, O. Hansson et al., "CSF biomarkers and incipient Alzheimer disease in patients with mild cognitive impairment," JAMA, vol. 302, no. 4, pp. 385-393, 2009.

[20] N. Mattsson, U. Andreasson, S. Persson et al., "The Alzheimer's Association external quality control program for cerebrospinal fluid biomarkers," Alzheimer's \& Dementia, vol. 7, no. 4, pp. 386-395.e6, 2011.

[21] J. Randall, E. Mörtberg, G. K. Provuncher et al., "Tau proteins in serum predict neurological outcome after hypoxic brain injury from cardiac arrest: results of a pilot study," Resuscitation, vol. 84, no. 3, pp. 351-356, 2013.

[22] H. Zetterberg, D. Wilson, U. Andreasson et al., "Plasma tau levels in Alzheimer's disease," Alzheimer's Research \& Therapy, vol. 5, no. 2, p. 9, 2013.

[23] M.-J. Chiu, L.-Y. Fan, T.-F. Chen, Y.-F. Chen, J.-J. Chieh, and H.-E. Horng, "Plasma tau levels in cognitively normal middle-aged and older adults," Frontiers in Aging Neuroscience, vol. 9, p. 51, 2017.

[24] J. L. Dage, A. M. V. Wennberg, D. C. Airey et al., "Levels of tau protein in plasma are associated with neurodegeneration and cognitive function in a population-based elderly cohort," Alzheimer's \& Dementia, vol. 12, no. 12, pp. 1226-1234, 2016.

[25] N. Mattsson, H. Zetterberg, S. Janelidze et al., "Plasma tau in Alzheimer disease," Neurology, vol. 87, no. 17, pp. 18271835, 2016.

[26] K. D. Deters, S. L. Risacher, S. Kim et al., "Plasma tau association with brain atrophy in mild cognitive impairment and Alzheimer's disease," Journal of Alzheimer's Disease, vol. 58, no. 4, pp. 1245-1254, 2017.

[27] H. Tatebe, T. Kasai, T. Ohmichi et al., "Quantification of plasma phosphorylated tau to use as a biomarker for brain Alzheimer pathology: pilot case-control studies including patients with Alzheimer's disease and down syndrome," Molecular Neurodegeneration, vol. 12, no. 1, p. 63, 2017.

[28] C. C. Yang, M. J. Chiu, T. F. Chen, H. L. Chang, B. H. Liu, and S. Y. Yang, "Assay of plasma phosphorylated tau protein (threonine 181) and total tau protein in early-stage Alzheimer's disease," Journal of Alzheimer's Disease, vol. 61, no. 4, pp. 1323-1332, 2018.

[29] M. M. Mielke, C. E. Hagen, J. Xu et al., "Plasma phosphotau181 increases with Alzheimer's disease clinical severity and is associated with tau- and amyloid-positron emission tomography," Alzheimer's \& Dementia, vol. 14, no. 8, pp. 989-997, 2018.

[30] M. Kolarova, U. Sengupta, A. Bartos, J. Ricny, and R. Kayed, "Tau oligomers in sera of patients with Alzheimer's disease and aged controls," Journal of Alzheimer's Disease, vol. 58, no. 2, pp. 471-478, 2017. 
[31] J. M. Tarasoff-Conway, R. O. Carare, R. S. Osorio et al., "Clearance systems in the brain-implications for Alzheimer disease," Nature Reviews Neurology, vol. 11, no. 8, pp. 457470, 2015.

[32] A. Chakraborty, N. M. De Wit, W. M. Van Der Flier, and H. E. De Vries, "The blood brain barrier in Alzheimer's disease," Vascular Pharmacology, vol. 89, pp. 12-18, 2017.

[33] N. Marchi, J. J. Bazarian, V. Puvenna et al., "Consequences of repeated blood-brain barrier disruption in football players," PLoS One, vol. 8, no. 3, article e56805, 2013.

[34] Z. Zhang, J. S. Zoltewicz, S. Mondello et al., "Human traumatic brain injury induces autoantibody response against glial fibrillary acidic protein and its breakdown products," PLoS One, vol. 9, no. 3, article e92698, 2014.

[35] A. Olivera, N. Lejbman, A. Jeromin et al., "Peripheral total tau in military personnel who sustain traumatic brain injuries during deployment," JAMA Neurology, vol. 72, no. 10, pp. 1109-1116, 2015.

[36] M. L. Alosco, Y. Tripodis, J. Jarnagin et al., "Repetitive head impact exposure and later-life plasma total tau in former National Football League players," Alzheimer's \& Dementia: Diagnosis, Assessment \& Disease Monitoring, vol. 7, pp. 3340, 2017.

[37] T. Bogoslovsky, D. Wilson, Y. Chen et al., "Increases of plasma levels of glial fibrillary acidic protein, tau, and amyloid $\beta$ up to 90 days after traumatic brain injury," Journal of Neurotrauma, vol. 34, no. 1, pp. 66-73, 2017.

[38] R. Rubenstein, B. Chang, J. K. Yue et al., "Comparing plasma phospho tau, total tau, and phospho tau-total tau ratio as acute and chronic traumatic brain injury biomarkers," JAMA Neurology, vol. 74, no. 9, pp. 1063-1072, 2017.

[39] M. S. Foiani, I. O. Woollacott, C. Heller et al., "Plasma tau is increased in frontotemporal dementia," Journal of Neurology, Neurosurgery \& Psychiatry, vol. 89, no. 8, pp. 804-807, 2018.

[40] T. Kasai, H. Tatebe, M. Kondo et al., "Increased levels of plasma total tau in adult Down syndrome," PLoS One, vol. 12, no. 11, article e0188802, 2017.

[41] A. J. Farrall and J. M. Wardlaw, "Blood-brain barrier: ageing and microvascular disease-systematic review and metaanalysis," Neurobiology of Aging, vol. 30, no. 3, pp. 337352, 2009.

[42] B. O. Popescu, E. C. Toescu, L. M. Popescu et al., "Bloodbrain barrier alterations in ageing and dementia," Journal of the Neurological Sciences, vol. 283, no. 1-2, pp. 99-106, 2009.

[43] A. Montagne, S. R. Barnes, M. D. Sweeney et al., "Blood-brain barrier breakdown in the aging human hippocampus," Neuron, vol. 85, no. 2, pp. 296-302, 2015.

[44] W. A. Banks, A. Kovac, P. Majerova, K. M. Bullock, M. Shi, and J. Zhang, "Tau proteins cross the bloodbrain barrier," Journal of Alzheimer's Disease, vol. 55, no. 1, pp. 411-419, 2017.

[45] K. Neumann, G. Farías, A. Slachevsky, P. Perez, and R. B. Maccioni, "Human platelets tau: a potential peripheral marker for Alzheimer's disease," Journal of Alzheimer's Disease, vol. 25, no. 1, pp. 103-109, 2011.

[46] G. Farías, P. Pérez, A. Slachevsky, and R. B. Maccioni, "Platelet tau pattern correlates with cognitive status in Alzheimer's disease," Journal of Alzheimer's Disease, vol. 31, no. 1, pp. 6569, 2012.

[47] A. Slachevsky, L. Guzmán-Martínez, C. Delgado et al., “Tau platelets correlate with regional brain atrophy in patients with Alzheimer's disease," Journal of Alzheimer's Disease, vol. 55, no. 4, pp. 1595-1603, 2017.

[48] E. B. Mukaetova-Ladinska, Z. Abdell-All, J. Andrade et al., "Platelet tau protein as a potential peripheral biomarker in Alzheimer's disease: an explorative study," Current Alzheimer Research, vol. 15, no. 9, pp. 800-808, 2018.

[49] M. S. Fiandaca, D. Kapogiannis, M. Mapstone et al., "Identification of preclinical Alzheimer's disease by a profile of pathogenic proteins in neurally derived blood exosomes: a case-control study," Alzheimer's \& Dementia, vol. 11, no. 6, pp. 600-607.e1, 2015.

[50] C. N. Winston, E. J. Goetzl, J. C. Akers et al., "Prediction of conversion from mild cognitive impairment to dementia with neuronally derived blood exosome protein profile," Alzheimer's \& Dementia: Diagnosis, Assessment \& Disease Monitoring, vol. 3, pp. 63-72, 2016.

[51] R. A. Stern, Y. Tripodis, C. M. Baugh et al., "Preliminary study of plasma exosomal tau as a potential biomarker for chronic traumatic encephalopathy," Journal of Alzheimer's Disease, vol. 51, no. 4, pp. 1099-1109, 2016.

[52] M. Mustapic, E. Eitan, J. K. Werner Jr. et al., "Plasma extracellular vesicles enriched for neuronal origin: a potential window into brain pathologic processes," Frontiers in Neuroscience, vol. 11, p. 278, 2017.

[53] M. Shi, A. Kovac, A. Korff et al., "CNS tau efflux via exosomes is likely increased in Parkinson's disease but not in Alzheimer's disease," Alzheimer's \& Dementia, vol. 12, no. 11, pp. 1125-1131, 2016.

[54] H. Rosenmann, Z. Meiner, V. Geylis, O. Abramsky, and M. Steinitz, "Detection of circulating antibodies against tau protein in its unphosphorylated and in its neurofibrillary tangles-related phosphorylated state in Alzheimer's disease and healthy subjects," Neuroscience Letters, vol. 410, no. 2, pp. 90-93, 2006.

[55] L. Fialová, A. Bartos, J. Švarcová, and I. Malbohan, "Increased intrathecal high-avidity anti-tau antibodies in patients with multiple sclerosis," PLoS One, vol. 6, no. 11, article e27476, 2011.

[56] M. Krestova, J. Ricny, and A. Bartos, "Changes in concentrations of tau-reactive antibodies are dependent on sex in Alzheimer's disease patients," Journal of Neuroimmunology, vol. 322, pp. 1-8, 2018.

[57] I. Kuhn, T. Rogosch, T. I. Schindler et al., "Serum titers of autoantibodies against $\alpha$-synuclein and tau in child- and adulthood," Journal of Neuroimmunology, vol. 315, pp. 3339,2018

[58] C. Bouras, B. M. Riederer, E. Kövari, P. R. Hof, and P. Giannakopoulos, "Humoral immunity in brain aging and Alzheimer's disease," Brain Research Reviews, vol. 48, no. 3, pp. 477-487, 2005.

[59] E. C. Levin, N. K. Acharya, M. Han et al., "Brain-reactive autoantibodies are nearly ubiquitous in human sera and may be linked to pathology in the context of blood-brain barrier breakdown," Brain Research, vol. 1345, pp. 221$232,2010$.

[60] A. Bartos, L. Fialova, and J. Svarcova, "Lower serum antibodies against tau protein and heavy neurofilament in Alzheimer's disease," Journal of Alzheimer's Disease, vol. 64, no. 3, pp. 751-760, 2018.

[61] A. Bartos, L. Fialová, J. Švarcová, and D. Ripova, "Patients with Alzheimer disease have elevated intrathecal synthesis 
of antibodies against tau protein and heavy neurofilament," Journal of Neuroimmunology, vol. 252, no. 1-2, pp. 100105, 2012.

[62] A. C. Klaver, M. P. Coffey, D. A. Bennett, and D. A. Loeffler, "Specific serum antibody binding to phosphorylated and non-phosphorylated tau in non-cognitively impaired, mildly cognitively impaired, and Alzheimer's disease subjects: an exploratory study," Translational Neurodegeneration, vol. 6, no. 1, p. 32, 2017.

[63] J. W. Terryberry, G. Thor, and J. B. Peter, "Autoantibodies in neurodegenerative diseases: antigen-specific frequencies and intrathecal analysis," Neurobiology of Aging, vol. 19, no. 3, pp. 205-216, 1998.

[64] M. Krestova, L. Hromadkova, Z. Bilkova, A. Bartos, and J. Ricny, "Characterization of isolated tau-reactive antibodies from the IVIG product, plasma of patients with Alzheimer's disease and cognitively normal individuals," Journal of Neuroimmunology, vol. 313, pp. 16-24, 2017.

[65] L. M. Smith, M. P. Coffey, A. C. Klaver, and D. A. Loeffler, "Intravenous immunoglobulin products contain specific antibodies to recombinant human tau protein," International Immunopharmacology, vol. 16, no. 4, pp. 424-428, 2013.

[66] L. M. Smith, M. P. Coffey, and D. A. Loeffler, "Specific binding of intravenous immunoglobulin products to tau peptide fragments," International Immunopharmacology, vol. 21, no. 2, pp. 279-282, 2014.

[67] L. Hromadkova, M. Kolarova, B. Jankovicova et al., "Identification and characterization of natural antibodies against tau protein in an intravenous immunoglobulin product," Journal of Neuroimmunology, vol. 289, pp. 121-129, 2015.

[68] D. A. Loeffler, A. C. Klaver, and M. P. Coffey, "ELISA measurement of specific antibodies to phosphorylated tau in intravenous immunoglobulin products," International Immunopharmacology, vol. 28, no. 2, pp. 11081112, 2015.

[69] S. K. Schroeder, A. Joly-Amado, M. N. Gordon, and D. Morgan, "Tau-directed immunotherapy: a promising strategy for treating Alzheimer's disease and other tauopathies," Journal of Neuroimmune Pharmacology, vol. 11, no. 1, pp. 9-25, 2016.

[70] D. A. Loeffler, "Should development of Alzheimer's diseasespecific intravenous immunoglobulin be considered?," Journal of Neuroinflammation, vol. 11, no. 1, p. 198, 2014.

[71] M. A. Sedykh, V. N. Buneva, and G. A. Nevinsky, "Polyreactivity of natural antibodies: exchange by HLfragments," Biochemistry (Moscow), vol. 78, no. 12, pp. 1305-1320, 2013.

[72] J. R. Willis, B. S. Briney, S. L. DeLuca, J. E. Crowe, and J. Meiler, "Human germline antibody gene segments encode polyspecific antibodies," PLoS Computational Biology, vol. 9, no. 4, article e1003045, 2013.

[73] S. Avrameas and T. Ternynck, "The natural autoantibodies system: between hypotheses and facts," Molecular Immunology, vol. 30, no. 12, pp. 1133-1142, 1993.

[74] A. F. Ochsenbein and R. M. Zinkernagel, "Natural antibodies and complement link innate and acquired immunity," Immunology Today, vol. 21, no. 12, pp. 624-630, 2000.

[75] F. Rossi, G. Dietrich, and M. D. Kazatchkine, "Anti-idiotypes against autoantibodies in normal immunoglobulins: evidence for network regulation of human autoimmune responses," Immunological Reviews, vol. 110, no. 1, pp. 135-149, 1989.
[76] T. Kieber-Emmons, B. Monzavi-Karbassi, A. Pashov, S. Saha, R. Murali, and H. Kohler, "The promise of the anti-idiotype concept," Frontiers in Oncology, vol. 2, p. 196, 2012.

[77] R. H. Scofield, "Autoantibodies as predictors of disease," The Lancet, vol. 363, no. 9420, pp. 1544-1546, 2004.

[78] A. Lleo, P. Invernizzi, B. Gao, M. Podda, and M. E. Gershwin, "Definition of human autoimmunity-autoantibodies versus autoimmune disease," Autoimmunity Reviews, vol. 9, no. 5, pp. A259-A266, 2010.

[79] R. Bayersdorf, A. Fruscalzo, and F. Catania, "Linking autoimmunity to the origin of the adaptive immune system," Evolution, Medicine, and Public Health, vol. 2018, no. 1, pp. 2-12, 2018.

[80] M. Z. Atassi, P. Casali, M. Z. Atassi, and P. Casali, "Molecular mechanisms of autoimmunity," Autoimmunity, vol. 41, no. 2, pp. 123-132, 2009.

[81] M. R. D'Andrea, "Add Alzheimer's disease to the list of autoimmune diseases," Medical Hypotheses, vol. 64, no. 3, pp. 458-463, 2005.

[82] M. R. D’Andrea, "Evidence linking neuronal cell death to autoimmunity in Alzheimer's disease," Brain Research, vol. 982, no. 1, pp. 19-30, 2003.

[83] K. Blennow, A. Wallin, F. Pam, G. Carl-Gerhard, I. Karlsson, and L. Svennerholm, "Intrathecal synthesis of immunoglobulins in patients with Alzheimer's disease," European Neuropsychopharmacology, vol. 1, no. 1, pp. 79-81, 1990.

[84] A. Abraha, N. Ghoshal, T. C. Gamblin et al., "C-terminal inhibition of tau assembly in vitro and in Alzheimer's disease," Journal of Cell Science, vol. 113, no. 21, pp. 3737$3745,2000$.

[85] J. C. Augustinack, A. Schneider, E. M. Mandelkow, and B. T. Hyman, "Specific tau phosphorylation sites correlate with severity of neuronal cytopathology in Alzheimer's disease," Acta Neuropathologica, vol. 103, no. 1, pp. 26-35, 2002.

[86] R. W. Berry, A. Abraha, S. Lagalwar et al., "Inhibition of tau polymerization by its carboxy-terminal caspase cleavage fragment," Biochemistry, vol. 42, no. 27, pp. 83258331, 2003.

[87] F. García-Sierra, N. Ghoshal, B. Quinn, R. W. Berry, and L. I. Binder, "Conformational changes and truncation of tau protein during tangle evolution in Alzheimer's disease," Journal of Alzheimer's Disease, vol. 5, no. 2, pp. 65-77, 2003.

[88] L. I. Binder, A. L. Guillozet-Bongaarts, F. Garcia-Sierra, and R. W. Berry, "Tau, tangles, and Alzheimer's disease," Biochimica et Biophysica Acta (BBA)-Molecular Basis of Disease, vol. 1739, no. 2-3, pp. 216-223, 2005.

[89] M. J. Guerrero-Muñoz, J. Gerson, and D. L. CastilloCarranza, "Tau oligomers: the toxic player at synapses in Alzheimer's disease," Frontiers in Cellular Neuroscience, vol. 9, p. 464, 2015.

[90] J. Wang, W. S. Jin, X. L. Bu et al., "Physiological clearance of tau in the periphery and its therapeutic potential for tauopathies," Acta Neuropathologica, vol. 136, no. 4, pp. 525-536, 2018.

[91] A. Durandy, S. V. Kaveri, T. W. Kuijpers et al., "Intravenous immunoglobulins-understanding properties and mechanisms," Clinical \& Experimental Immunology, vol. 158, pp. 2-13, 2009.

[92] S. Zivkovic, "Intravenous immunoglobulin in the treatment of neurologic disorders," Acta Neurologica Scandinavica, vol. 133, no. 2, pp. 84-96, 2016. 
[93] M. C. Dalakas, "Use of intravenous immunoglobulin in neurology," in Antibody Therapy, pp. 101-109, Springer, Cham, 2018.

[94] N. Relkin, "Clinical trials of intravenous immunoglobulin for Alzheimer's disease," Journal of Clinical Immunology, vol. 34, no. S1, pp. 74-79, 2014.

[95] N. R. Relkin, R. G. Thomas, R. A. Rissman et al., "A phase 3 trial of IV immunoglobulin for Alzheimer disease," Neurology, vol. 88, no. 18, pp. 1768-1775, 2017.

[96] M. Okuya, S. Matsunaga, T. Ikuta, T. Kishi, and N. Iwata, "Efficacy, acceptability, and safety of intravenous immunoglobulin administration for mild-to-moderate Alzheimer's disease: a systematic review and meta-Analysis," Journal of Alzheimer's Disease, vol. 66, no. 4, pp. 1379-1387, 2018.

[97] M. Boada, E. Ramos-Fernández, B. Guivernau et al., "Treatment of Alzheimer disease using combination therapy with plasma exchange and haemapheresis with albumin and intravenous immunoglobulin: rationale and treatment approach of the AMBAR (Alzheimer Management By Albumin Replacement) study," Neurología, vol. 31, no. 7, pp. 473-481, 2016.

[98] J. Cummings, G. Lee, T. Mortsdorf, A. Ritter, and K. Zhong, "Alzheimer's disease drug development pipeline: 2017," Alzheimer's \& Dementia: Translational Research \& Clinical Interventions, vol. 3, no. 3, pp. 367-384, 2017.

[99] N. Svetlicky, O. D. Ortega-Hernandez, L. Mouthon et al., "The advantage of specific intravenous immunoglobulin (sIVIG) on regular IVIG: experience of the last decade," Journal of Clinical Immunology, vol. 33, no. S1, pp. 27-32, 2013.

[100] D. Lejtenyi and B. Mazer, "Consistency of protective antibody levels across lots of intravenous immunoglobulin preparations," Journal of Allergy and Clinical Immunology, vol. 121, no. 1, pp. 254-255, 2008.

[101] S. Cattepoel, A. Gaida, A. Kropf, M. W. Nolte, R. Bolli, and S. M. Miescher, "Effect of IVIG formulation on IgG binding to self- and exo- antigens in vitro and in vivo," PLoS One, vol. 11, no. 8, article e0161826, 2016.

[102] D. A. Loeffler and A. C. Klaver, "Polyvalent immunoglobulin binding is an obstacle to accurate measurement of specific antibodies with ELISA despite inclusion of blocking agents," International Immunopharmacology, vol. 52, pp. 227229, 2017.

[103] L. Hromádková, Tau protein, a biomarker of Alzheimer's disease: in vitro phosphorylation and tau-reactive antibodies characterization, [Ph.D. thesis], Department of Physiology, Charles University, Prague, Czech Republic, 2018.

[104] L. Fialová, J. Švarcová, A. Bartos, and I. Malbohan, “Avidity of anti-neurocytoskeletal antibodies in cerebrospinal fluid and serum," Folia Microbiologica, vol. 57, no. 5, pp. 415419, 2012.

[105] Y. Kronimus, A. Albus, M. Balzer-Geldsetzer et al., "Naturally occurring autoantibodies against tau protein are reduced in Parkinson's disease dementia," PLoS One, vol. 11, no. 11, article e0164953, 2016.

[106] M. Krestova, L. Hromadkova, and J. Ricny, "Purification of natural antibodies against tau protein by affinity chromatography," in Natural Antibodies. Methods in Molecular Biology, vol 1643, S. Kaveri and J. Bayry, Eds., pp. 33-44, Humana Press, New York, NY, USA, 2017. 


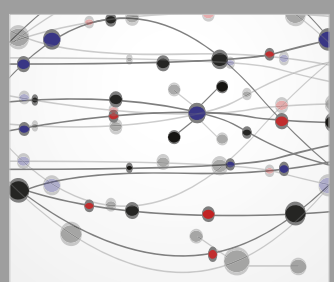

The Scientific World Journal
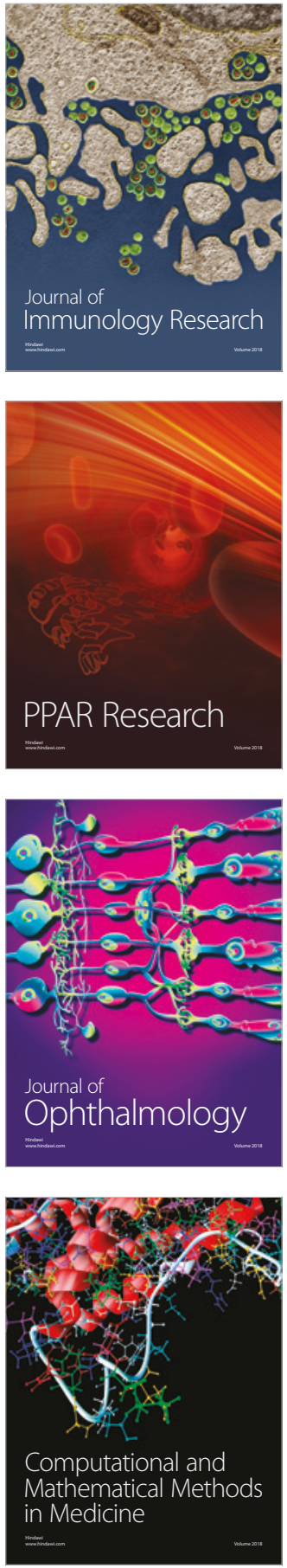

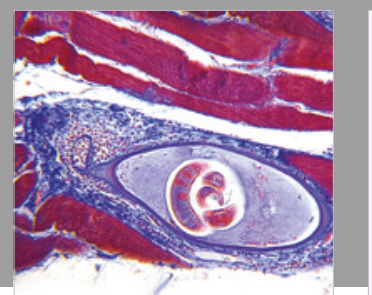

Gastroenterology Research and Practice

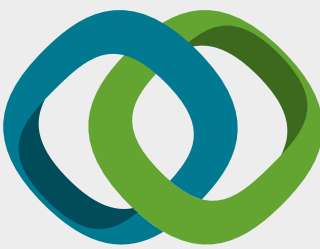

\section{Hindawi}

Submit your manuscripts at

www.hindawi.com
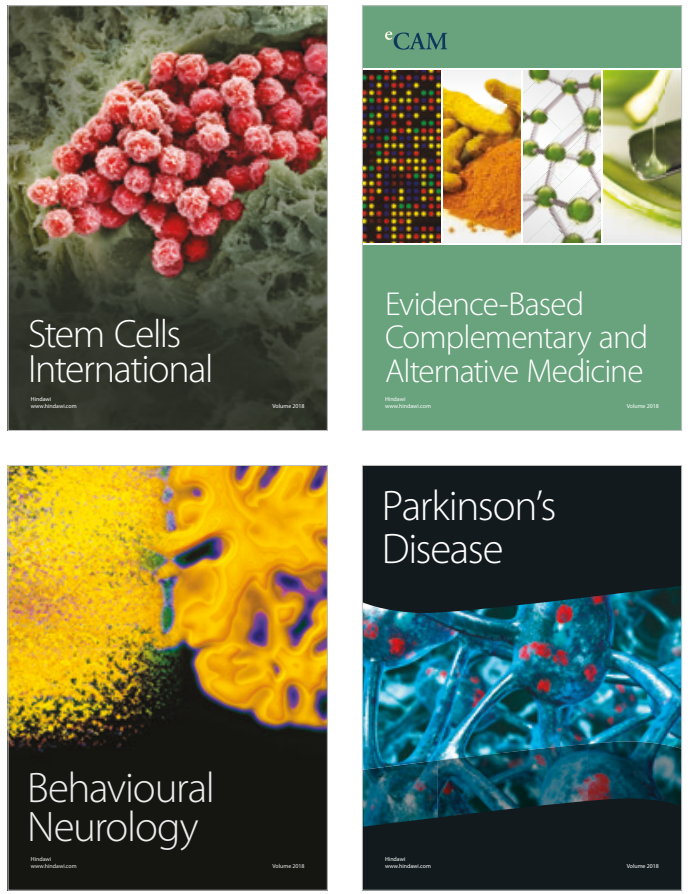

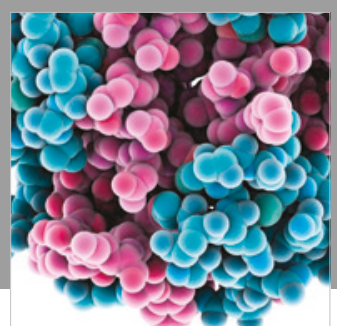

ournal of

Diabetes Research

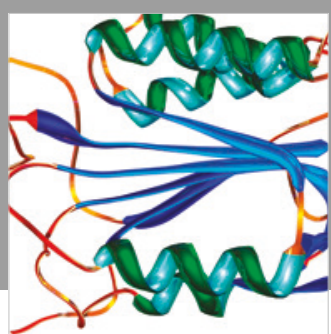

Disease Markers
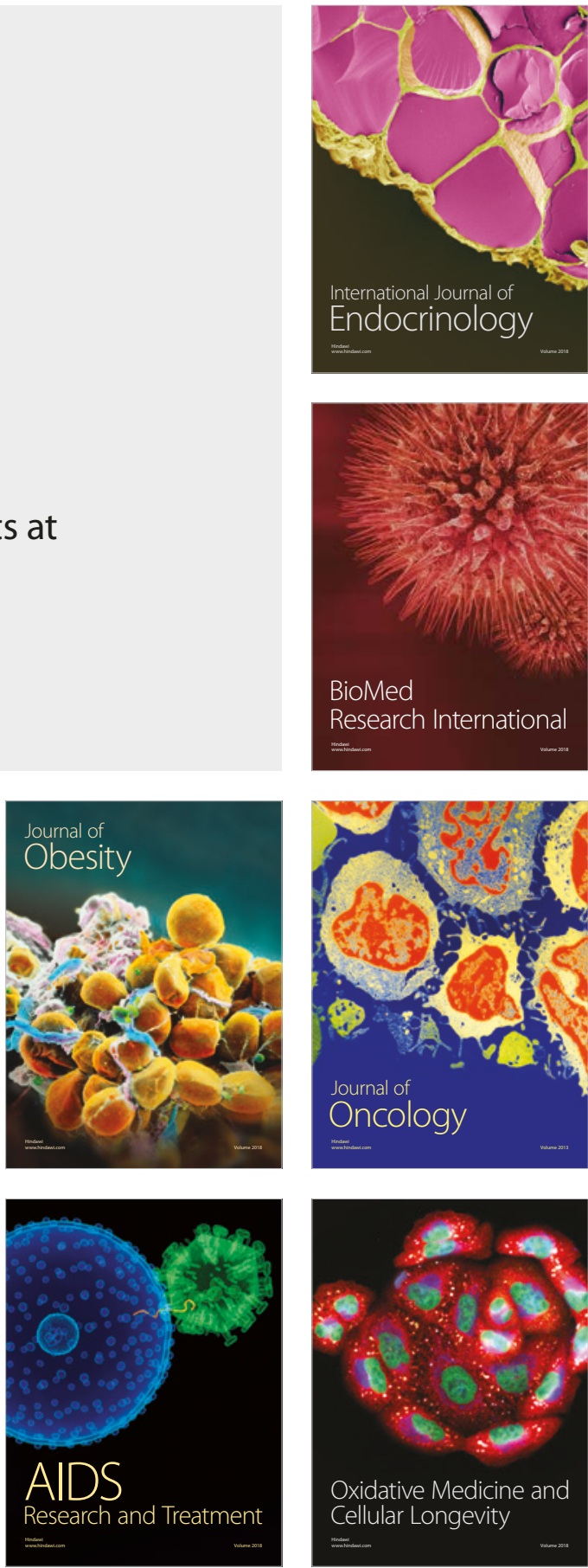